\title{
Non-inflatable Penile Prosthesis for the Management of Urinary Incontinence and Sexual Disability of Patients with Spinal Cord Injury
}

Eiji Iwatsubo, M.D., Ph.D., Makoto Tanaka, M.D., Koichi Takahashi, M.D. and Takashi Akatsu, M.D., Ph.D.

Iizuka Spinal Injuries Center, Iizuka, Fukuoka 820, Japan

\begin{abstract}
Summary
During the last 5 years non-inflatable penile prostheses were implanted in 37 patients with spinal cord injury. Operation was done to provide adequate stability of the penis in order to hold an external urinary device, to help erectile impotence and to make self-catheterisation easier. A pair of Shirai-type silicone penile implants were inserted into the corpora cavernosa through a dorsal skin incision at the penile base. In 37 patients 33 had excellent results. Extrusion of the prosthesis occurred in two cases due to infection. Removal of the prosthesis was necessary in a patient who had causalgia in the lower extremities. Posterior migration of the prosthesis was noted in a tetraplegic patient who used to turn on his stomach when he changed clothes. Anterior sphincterotomy which was performed during the surgery in one case and after the surgery in another two cases did not affect the prosthesis. Questionnaire survey revealed that $32\left(86^{\circ}{ }_{0}\right)$ were satisfied with the procedure which provided better condom fitting and easier intermittent catheterisation whereas only $5\left(14^{\circ}{ }_{0}\right)$ were dissatisfied. The prosthesis improved sexual function in $15\left(41^{\circ}{ }_{0}\right)$ patients, 18 $\left(48^{\circ}{ }_{0}\right)$ patients were unchanged and four $\left(11_{0}^{\circ}\right)$ patients were dissatisfied. Penile prosthesis is an effective manoeuvre for the treatment of urinary incontinence and sexual disability of patients with spinal cord injury provided that the special aspects of the spinal cord injury is taken into consideration.
\end{abstract}

Key words: Penile prosthesis; Spinal cord injury; Urinary appliance; Erectile impotence.

\section{Introduction}

Patients with spinal cord injury are frequently troubled by difficulties in applying urinary devices and it has already been reported that the penile prosthesis is 
effective in reducing the incidence of this by making the penile shaft stable for the secure application of the device.

\section{Materials and method}

Thirty-seven patients with spinal cord injury (10 tetraplegics, 23 paraplegics and four walking patients with cauda equina lesions) aged from 21 to 63 years (average 42 years) received the implant. 27 patients with upper motor neuron bladders under trigger voiding wore a urinary condom. Eighteen $\left(67^{\circ}{ }_{0}\right)$ of these patients had difficulty in maintaining the appliance, experiencing such problems as dermatitis, and oedematous swelling or ulceration of the penis. The remaining 10 patients used self-catheterisation and had no urinary incontinence but were impotent.

The Shirai-type implant is made of silicone in the shape of a flat rib. The tip, $1 \mathrm{~cm}$ long, and base $3 \mathrm{~cm}$ long, is soft and flexible to reduce direct force to the glans and crus and it can be bent at the basal portion. The mid portion is rigid. The sizes of penile implant which were frequently used were 12 and 13 $\mathrm{cm}$ in length and $3 \mathrm{~cm}$ in circumference (Fig. 1). A pair of penile implants were inserted into each corporus cavernosum through a dorsal incision. The observation period of this study was from 6 to 46 months (average 19 months).

\section{Results}

Thirty-three cases $\left(89^{\circ}{ }_{0}\right)$ were successful but in two cases $\left(5^{\circ}{ }_{0}\right)$ extrusion of the penile implants due to wound infection occurred on the 30th and 40th postoperative days. All the 18 patients who had suffered from difficulty in fitting the urinary condom became free from skin disorders of the penis. Most of the patients under self-catheterisation stated that the elongated and firm penis facilitated the catheterisation. A 46-year-old paraplegic with a complete lesion below T 12 who had suffered from causalgia for the past 20 years, insisted that the implant made the pain unbearable. The implants were removed 2 months post-operatively. Pain intensity returned to the pre-operative level. A 29 -year-old tetraplegic (C7 complete lesion) noticed irritation of the perineal region at 3 months post-operatively and posterior migration of the implant was disclosed. He used to turn on his stomach when he changed clothes and direct compression force on the tip of the penis was considered to be the cause for this displacement.

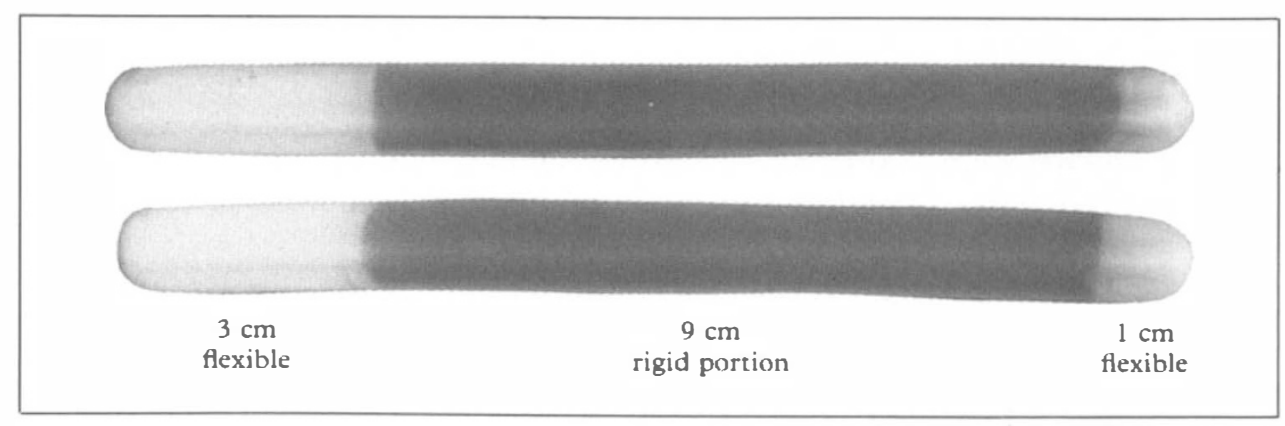

Figure Shirai-type Penile Implants and their Location in Cavernosum Penis 
A cavernogram delineated a cystic cavity in which the penile implant was displaced caudally. The posterior migration of the rods was corrected by transperineal closure of the cystic cavity using Dexon stitch ligation.

There was no aggravation of dysuria in these 35 cases, and erection which existed before the implant in some cases persisted unchanged after the implant. Transurethral operations were performed as necessary before or after the implant. Anterior sphincterotomy was performed on the same day in one, and at 8 months and 3 years after surgery in two patients. Transurethral resection of bladder neck and prostate was performed 3 months post-operatively in one patient. These transurethral operations did not affect the prosthesis. In a questionnaire survey, 32 cases $\left(86^{\prime \prime}{ }_{0}\right)$ expressed themselves satisfied with the result of surgery because of better condom fitting and easier intermittent catheterisation, while five $\left(14^{\circ}{ }_{0}\right)$ were dissatisfied.

With reference to sexual aspects, 15 patients $\left(41^{\prime \prime}{ }^{\prime}\right)$ ) reported that their marital life was improved and they were encouraged with it. 18 cases $\left(48^{\prime \prime}{ }^{\prime \prime}\right)$ reported that they had no benefit. Ten of them were single, four were rejected by their wives and four had not had enough opportunity to try sexual intercourse. Four patients expressed dissatisfaction. The patient with unilateral extrusion of the implant, and the obese man with a concealed penis could not carry out satisfactory intercourse. Two patients complain of dissatisfactory sexual life since the implant was too small.

\section{Discussion}

Many of the non-inflatable penile prostheses previously reported are either of the Finney or Small-Carrion type. These are made of silicone in the shape of round rods and were reported to be effective in patients with spinal cord injury. The Shirai-type penile implant used in the study is also made of silicone but is in the shape of a flat rib. This shape is more physiological than the round rod and may protect the urethra since they can be scarcely inserted beneath the tunica albuginea. This structural consideration seemed to be effective in preventing dysuria and also enabled transurethral surgery although it has been recommended that this should be avoided after the prosthesis operation (Golji 1979; Rossier and Fam, 1984; Smith et al., 1980). Pain at the site of the implant, when present, may be expected to disappear within a few weeks but in this series the paraplegic patient with causalgia who had analgesia below T 12 without sacral sparing, complained post-implant of aggravation of the causalgia which was located in the lower extremities. The patient insisted that aggravation of the causalgia resulted from the operation although he had no pain at the site of the implant. It must be stressed that the psychological background of patients should always be considered especially those who have causalgia or phantom pain. Extrusion or backward migration of the implant is a major complication (Chaikin et al., 1981; Finney et al., 1980; Van Arsdalen et al., 1981) especially in patients with spinal cord injury since the tunica albuginea seems to be thin. If strong forces are repeatedly applied to the tip of the penis, the prosthesis will gradually migrate posteriorly. 


\section{Conclusion}

Shirai-type prostheses were implanted in 37 patients with spinal cord injury. $89^{\circ}{ }_{0}$ of patients were satisfied with the result. The Shirai-type prosthesis is successful in eradicating the difficulties in fitting urinary condoms and may facilitate self-catheterisation. Inadequate sexual function may be improved. The selection of the implant, prevention of infection and avoidance of pressure by education of the patient are mandatory.

\section{Resumé}

Au cours de ces 5 dernières années, on a procédé à l'implantation de prothèses péniennes semi-rigides chez 37 traumatisés médullaires. En plus de son but visant à rétablir un certain degré de puissance sexuelle, l'intervention a cherché à assurer une stabilité pénienne suffisante permettant le port adéquat d'un collecteur d'urine externe et facilitant l'auto-sondage itératif.

C'est par une incision curanée à la partie dorsale de la base du pénis que deux prothèses péniennes en silicone, du type Shirai, de configuration aplatie, similaire à celle d'une côte, ont été insérées dans les corps caverneux. Les résultats ont été excellents chez 33 des 37 patients. Il y eut deux extrusions par surinfection locale. Il fallut enlever les prothèses chez un patient dont les douleurs causalgiques avaient été aggravées par l'insertion de ces corps étrangers. Il y eut une migration postérieure des prothèses chez un tétraplégique qui se mettait en position ventrale pour changer d'habits. Il n'y eut par contre aucune complication chez un patient dont la sphinctérotomie antérieure fut faite au même moment et chez deux autres après l'insertion des prothèses.

Un questionnaire adressé aux patients a révélé que $32\left(86^{\prime \prime}{ }_{11}\right)$ d'entre eux étaient satisfaits du procédé-meilleure fixation du condom et sondages itératifs plus faciles-, alors que 5 (14" $\left.1{ }^{\prime \prime}\right)$ étaient d'un avis opposé. Sur le plan sexuel, $15\left(41^{\prime \prime}{ }^{\prime}\right)$ étaient satisfaits de l'opération, $18\left(48^{\prime \prime}{ }^{\prime}\right)$ ne voyaient aucune différence, et $4\left(11^{\circ}{ }^{\prime}\right)$ étaient insatisfaits.

Les prothèse péniennes représentent un moyen efficace du traitement de l'incontinence urinaire et de l'impuissance sexuelle chez les traumatisés médullaires, pour autant que les caractéristiques qui leur sont propres soient prises en considération.

\section{References}

Chaikin L, Carrion H, Politano V 1981 Complications of the Small-Carrion Penile Prosthesis: Long-term Follow-up. Journal of Urology 126:44-45.

Finney RP, Sharpe JR, SAdlowski RW, 1980 Finney Hinged Penile Implant: Experience with 100 Cases. Journal of Urology 124:205-207.

Golji H 1979 Experience with Penile Prosthesis in Spinal Cord Injury Patients. Journal of Urology 288-289.

Rossier AB, FAM BA 1984 Indication and Results of Semirigid Penile Prostheses in Spinal Cord Injury Patients: Long-term Follow-up. Journal of Urology 59-62.

Smith AD, Sazama R, Lange PH 1980 Penile Prosthesis: Adjunct to Treatment in Patients with Neurogenic Bladder. Journal of Urology 363-364.

Van Arsdalen KN, Klein FA, Hackler RH, et al. 1981 Penile Implants in Spinal Cord Injury Patients for Maintaining External Appliances. Journal of Urology 331-332. 